\title{
Contribuições dos letramentos digital e informacional na sociedade contemporânea
}

\section{Contributions of digital and information literacies in contemporary society}

\author{
Isabel Cristina Michelan de AZEVEDO' ${ }^{1}$ \\ Kelley Cristine Gonçalves Dias GASQUE²
}

\section{Resumo}

O presente artigo discute a importância dos letramentos digital e informacional na contemporaneidade, por serem considerados processos essenciais na sociedade da aprendizagem. Em tempos líquidos, nos quais se observa o enfraquecimento dos vínculos humanos, é necessário promover a ampla formação dos sujeitos para que possam construir posicionamentos críticos, conscientes e direcionados ao bem comum. Foram analisadas práticas sociais e culturais que constituem as identidades dos indivíduos, além de algumas estratégias de ação que possibilitam aprendizagens mais significativas, com base em estudos das ciências cognitivas e das neurociências. Pesquisas mostram que os meios provocam comportamentos específicos que impactam as aprendizagens, por isso é fundamental identificar as forças que permitem aos sujeitos ir além da aquisição dos conhecimentos, tendo em vista o uso de diferentes capacidades diante dos desafios cotidianos individuais e sociais, bem como o desenvolvimento da solidariedade.

Palavras-chave: Aprendizagem. Letramento digital. Letramento informacional.

\begin{abstract}
The aim of the present article is to discuss the importance of digital and information literacies in contemporaneity as they are considered essential processes in the learning society. In 'liquid times' when one observes the weakening of human bonds, it is imperative to promote the broadening of human education so that one can build critical, conscious, and direct positions toward the common good. Social and cultural practices that constitute the identities of individuals and some action strategies that enable more meaningful learning were analyzed based on studies in cognitive science and neuroscience. Research shows that the media cause specific behaviors that impact learning and, for this reason, it is essential to identify the forces that allow subjects to go beyond the acquisition of knowledge, considering how different capacities are used to deal with the individual and social day to day challenges, as well as social development and solidarity.
\end{abstract}

Keywords: Learning. Digital literacy. Information Literacy.

\section{Introdução}

O letramento digital e o informacional estão relacionados a diferentes áreas de conhecimento e decorrem de fatores psicológicos, culturais, sociais, econômicos e, em especial, cognitivos, pesquisados por grupos que realizam trabalhos diversificados, mas complementares. Em uma perspectiva dinâmica, para

\footnotetext{
1 Universidade Federal do Sergipe, Centro de Educação e Ciências Humanas, Departamento de Letras Vernáculas. São Cristóvão, SE, Brasil.

2 Universidade de Brasília, Faculdade de Ciências da Informação, Programa de Pós-Graduação em Ciência da Informação. Campus Universitário Darcy Ribeiro, Asa Norte, 70910-970, Brasília, DF, Brasil. Correspondência para/Correspondence to: K.C.G.D. GASQUE. E-mail:<kelleycristinegasque@hotmail.com>. Recebido em 26/6/2014, reapresentado em 26/11/2014 e aprovado para publicação em 14/3/2016.
} 
estudá-los é preciso integrar informações e pontos de vista, considerando a ampliação das análises possíveis.

Segundo Bauman (2007, p.9), na parte "desenvolvida" do planeta, observa-se a passagem da fase sólida para a líquida, o que define a sociedade como uma rede (não mais como estrutura) que serve como uma "matriz de conexões e desconexões aleatórias e de um volume essencialmente infinito de permutações possíveis". Nessa realidade, cujo terreno é instável e indeterminado, torna-se fundamental investigar os meios que possibilitam a participação mais efetiva dos sujeitos na vida social.

Diante da insegurança do presente, da incerteza do futuro e da impossibilidade de controle das circunstâncias, a proposta da Organização das Nações Unidas (ONU) de promover o letramento, como forma de emancipação das pessoas em um mundo globalizado, parece ser uma alternativa para o pleno desenvolvimento dos sujeitos em tempos líquidos.

O termo literacy, na década de 80 , foi utilizado para explicar a aquisição das competências de leitura e escrita; por isso, estava associado à alfabetização, que representa os processos de apropriação do código linguístico em situações reais de uso da língua (TFOUNI, 2002). Mesmo nessa visão individualista-restritiva, o conceito já aponta a necessidade de propostas sociais direcionadas à potencialização das pessoas por meio do domínio da linguagem.

No Brasil, no âmbito da educação, literacy tem sido traduzido pelo termo letramento e acompanha a tendência internacional que, atualmente, o adota em múltiplas perspectivas. Ao representar o estado ou letradas exercerem efetivamente as práticas sociais de leitura e escrita, orienta a observação para o quanto os eventos de letramento têm se expandido dia a dia - sobretudo, considerando as novas possibilidades da cibercultura, que, ao introduzir as tecnologias de comunicação eletrônica como alternativa aos meios de comunicação tradicionais (rádio, televisão, jornais, revistas, etc.), promove novas atitudes, formas de interação, competências cognitivas e discursivas entre as pessoas em geral e, em particular, entre estudantes e educadores (SOARES, 2002).
As novas tecnologias de informação e comunicação são instrumentos de práticas de leitura e escrita diferenciadas e desempenham papel importante na organização/reorganização do estado e da condição das pessoas ou grupos, durante as interações estabelecidas cotidianamente. Tais tecnologias são incluídas por Levy (1993) entre as tecnologias intelectuais, porque geram estilos de pensamento diferentes e condicionam processos cognitivos e discursivos. Desenvolvidas preponderantemente em ambientes colaborativos, permitem ao sujeito passar de um indivíduo pensante para integrar uma ecologia cognitiva que inclui as mentes humanas e as redes técnicas de armazenamento, transformação e partilha das representações.

As imagens, ideias e enunciados construídos coletivamente configuram representações sobre o mundo, as pessoas e as concepções, elaboradas em particular ou em conjunto, constituindo uma globalidade composta pelas manifestações de cada um. A composição, decorrente das inúmeras participações, assume, então, uma identidade própria que precisa ser conhecida, quando se quer promover valores, comportamentos e intenções em favor do bem comum.

Diante disso, o presente artigo discute a importância do letramento digital, processo essencial na sociedade da aprendizagem, por parecer ser uma alternativa para tornar os vínculos humanos menos frouxos, mas, por isso mesmo, terrivelmente precários, e étão difícil praticar a solidariedade quanto compreender seus benefícios, e mais ainda suas virtudes morais. Ao mesmo tempo, apresenta a necessidade de se ampliar a busca e o uso de recursos e fontes de informação incluídos no letramento informacional -, bem como as atividades que são necessárias à aprendizagem do referido processo, considerando os fundamentos das ciências cognitivas e das neurociências. Pesquisas recentes (MERZENICH, 2012; SMALL; VORGAN, 2008) mostram que os meios provocam comportamentos específicos que impactam as aprendizagens, de modo que se torna fundamental identificar as forças que permitem aos sujeitos ir além da aquisição dos conhecimentos, tendo em vista o uso de diferentes capacidades e o desenvolvimento da solidariedade, 
especialmente quando são confrontados por desafios individuais e sociais.

\section{Letramento digital}

Por mais de uma década, o termo 'geração digital' - difundiu-se a partir do trabalho de Tapscott (1999). Em geral tem sido utilizado para descrever o crescimento do acesso de crianças e jovens ao mundo das tecnologias de informação e comunicação e a diferenciação no modo como eles fazem uso de tais recursos. O termo caracteriza um grupo que utiliza novos modos de ler e escrever os códigos e sinais verbais e não verbais, transformando, assim, o conteúdo da atividade cerebral, que reside nos padrões de conexão e de atividade entre neurônios. As diferenças nos detalhes das conexões, mesmo quando minúsculas, podem fazer com que ocorra nas mentes o fortalecimento de processos específicos, exaustivamente exercitados, o que permite ao cérebro realizar atividades bastante diferentes de outros grupos que não passam pela mesma experiência (MERZENICH, 2004; PINKER, 1998).

Embora sejam diferenças funcionais (não estruturais), diante de tais constatações, segundo Choudhury e McKinney (2013), Mellow (2005) e Prensky (2001, 2011), o mais relevante não é investigar as diferenças entre imigrantes e nativos digitais, mas entender que, devido à plasticidade cerebral, pode-se considerar que pessoas jovens estão biologicamente mais aptas para aprender de modo diferenciado e interativo, característica que se opõe a sistemas educacionais rígidos, pouco criativos e fundamentados em um número restrito de metodologias.

O letramento depende das práticas sociais e culturais, historicamente situadas, nas quais os sujeitos estão implicados, e está associado aos diferentes domínios da vida. Como os contextos são muito distintos, assim como as comunidades e culturas, identifica-se uma grande variedade de práticas e eventos letrados, o que justifica considerar os multiletramentos com os quais todos os sujeitos se confrontam continuamente (BARTON; RAMILTON, 1998). Em função disso, decidiu-se refletir acerca de como os vários tipos de letramentos estão modificando a aprendizagem e, consequentemente, a estrutura cerebral dos estudantes que estão na escola e em vários outros ambientes sociais.

Ao observar que a geração digital é capaz de reconstruir a memória coletiva, de integrar semioses, de transmutar os gêneros textuais existentes e de rejuvenescer a escrita por meio de um constante processo de hibridização ou de bricolagem de narrativas, dentre outros procedimentos, ressalta-se a configuração de um estado ou condição com diferenciais suficientes para definir o que vem sendo chamado de letramento digital.

Por estar vinculado às inovações tecnológicas, - letramento digital acompanha a evolução dos contextos tecnológico, econômico, social, cultural e político de uma dada sociedade e requer o domínio da língua escrita. Há uma inegável condicionalidade entre o letramento digital e o letramento alfabético, como pode ser visto, por exemplo, na utilização de um processador de texto: a escrita na tela, a edição das partes do texto, a seleção de trechos e a colagem de textos, parágrafos, frases, etc., indicam essa relação de dependência (XAVIER, 2007).

A especificação do conceito de letramento em letramento digital está apoiada na interação favorecida por diferentes ambientes que dependem da expansão das Tecnologias de Informação e Comunicação (TIC) e da Web. Além de indicar que nas práticas de leitura e escrita é possível integrar experiências do convívio social, tendo em vista novas formas de participação social.

O leitor proficiente na leitura de textos lineares desenvolve regiões cerebrais especializadas, que estão conectadas para representar e recuperar informações visuais, fonológicas e semânticas. Há conjuntos de neurônios dedicados a reconhecer, em questão de milissegundos, imagens visuais de letras e palavras. O cérebro mais apto nesse exercício, ou seja, mais eficiente e atento, torna esse processo automático, por isso pode dedicar mais recursos à interpretação do significado (CARR, 2011). Ao retomar as ideias de McLuhan (1969) de que os meios não são meramente canais de informação, mas também moldam o processo do pensamento, este breve estudo propõe-se a indicar como e quanto o contato frequente com mídias digitais impacta o modo como a mente funciona. 
A interação de crianças e jovens com as tecnologias digitais gera sujeitos que pensam e processam informações de um modo fundamentalmente diferente de seus predecessores, uma vez que diferentes tipos de experiências produzem diferentes estruturas cerebrais, segundo Merzenich (2004), Perry (1995) e Small e Vorgan (2008), dentre outros neurocientistas. O desenvolvimento dessas tecnologias permite a ampliação dos ambientes sociais reais e a multiplicação de oportunidades para lidar com as informações disponíveis na sociedade. Isso favorece uma atividade extensiva em todas as regiões cerebrais, especialmente quando os sujeitos vasculham e buscam Web pages, estimulando, em particular, a atividade nas regiões pré-frontais associadas à tomada de decisões e à resolução de problemas, dentre outras capacidades.

Como a cognição e a atividade social são fundamentalmente interdependentes, pode-se afirmar que o pensamento é uma atividade coletiva - que se desenvolve na medida em que o homem acumula experiências e coopera socialmente - e que as relações sociais, individuais ou de grupos impactam cada informação processada na mente (DEWEY, 1978; MOSKOWITZ, 2005). Em uma perspectiva muito próxima das pesquisas sobre cognição social (ADOLPHS, 1999; FISKE; TAYLOR, 1991; MOSKOWITZ, 2001), propõe-se, então, uma análise integrada entre as bases biológicas do desenvolvimento, a variabilidade cultural e os contextos histórico-sociais. Considerando que essas dimensões definem a forma como o sujeito pensa os outros e a si próprio, a compreensão do letramento digital deverá incluir, além dos objetos e eventos sociais, as relações entre as ações, os pensamentos e os sentimentos próprios e alheios. Dessa maneira, pode-se investigar a organização dos conceitos sociais e a habilidade de integrar e coordenar perspectivas.

É possível verificar que os sujeitos letrados digitalmente participam ativamente dos processos de apropriação e construção dos conhecimentos, bem como da construção coletiva de habilidades e competências e da definição de temas e ações, o que suscita motivação pessoal e coletiva e evidencia a capacidade de criar novas possibilidades de representar o mundo. Isso porque, considerando a pesquisa de Anderson (1991), eles parecem ser mais estimulados a recorrer às frequentes informações acessadas na categorização das percepções; a inferir, ou seja, a produzir novos conteúdos semânticos a partir de informações conhecidas e/ou de experiências vividas, especialmente quando são analisadas as causas e as consequências das ações; a fazer predições a partir das inferências construídas e a tomar decisões baseadas em atividades já realizadas ou na probabilidade de novos acontecimentos, o que permite responder apropriadamente às circunstâncias inusitadas.

Por outro lado, observa-se também uma dispersão da atenção e pouca facilidade na prática da leitura profunda, provocando certa dificuldade na retenção de informações. Os leitores digitais, que transitam entre diferentes materiais, precisam de tempo maior para incorporar o grande volume de informações, provocando uma redução da atenção necessária para a assimilação e aprofundamento dos conteúdos. Como o cérebro recicla os neurônios e as sinapses não utilizadas, os recursos digitais estimulam a alteração das células cerebrais e a liberação de neurotransmissores, fortalecendo novas vias neurais enquanto as mais antigas são enfraquecidas (CARR, 2011). A natureza não linear do hipertexto, por exemplo, altera a ordem hierárquica da composição e interpretação de textos.

No entanto, o hipertexto favorece também novas relações sociais e provoca mudanças relativas à autoridade intelectual por ideias, palavras e ações. Sem necessidade de permissão ou apoio de qualquer instituição formalmente organizada, sujeitos emancipam-se e engajam-se na produção de realidades sociais inexistentes anteriormente. Um mundo rigidamente organizado em classes, castas, grupos, com autoridade reconhecida nacional e internacionalmente, é revisto na perspectiva de um mundo integrado, globalizado, multicultural, sem barreiras físicas ou temporais e sem limites à participação pessoal ou coletiva (XAVIER, 2004). Um exemplo dessa nova realidade pode ser visto desde 2001, quando jovens japonesas começaram a compor histórias nos seus celulares e, depois, faziam upload delas em um website. Os 'romances de celular', escritos em capítulos, ganharam tanta popularidade (com milhões de leitores online) que viraram best-sellers no país, depois de publicados em livros impressos, como foi noticiado pela imprensa internacional (FARRAR, 2009; ONISHI, 2008). 
Outra característica relevante do letramento digital é a promoção de experiências sinestésicas. No ambiente colaborativo do hipertexto, os arranjos textuais, as imagens, os sons e as animações permitem ao sujeito vivenciar situações que estimulam o pensamento, os sentimentos, os anseios, os sonhos. A Internet envolve os sentidos simultaneamente, em especial a visão e a audição. O conjunto de diferentes aportes sígnicos em um único suporte de leitura estimula o sujeito, indicando caminhos e despertando reações inesperadas. Ao fazer emergir associações imprevisíveis, os estímulos digitais recompensam o esforço exigido para o acompanhamento ea assimilação das informações, mas, ao mesmo tempo, sobrecarrega a atividade mental com solicitações de respostas instantâneas. Cria-se, assim, um vínculo profundo e difícil de ser rompido, pois a interatividade é ampliada tanto pelos símbolos e estímulos provenientes dos dispositivos típicos do meio digital, quanto pelas pessoas que participam de vários contextos sociais.

Nos novos espaços, percebidos subjetivamente, ocorrem diálogos que podem superar preconceitos e diferenças, além de instigar a curiosidade e o espírito investigativo. As experiências são complexas, diversificadas, livres, mas se apoiam em convicções firmes, ou seja, na identidade que os módulos cerebrais adquirem mediante a combinação dos neurônios, dos padrões de inputs recebidos ao longo da evolução humana e das interações estabelecidas com as outras pessoas (PINKER, 1998). Com base na própria observação e reflexão, os sujeitos assumem diferentes comportamentos que podem variar do senso de contestação à tolerância às diferenças, mas que incentivam a busca de soluções para problemas cotidianos, a responsabilidade social e a mobilização criativa, dentre outras atitudes.

A deslinearização, aliada às experiências multissensoriais, delineia uma identidade não hierárquica, interpessoal e multicultural, que só pode ser compreendida dentro de processos de produção simbólica e discursiva. Como tal identidade oscila entre os movimentos de estabilização e subversão, parece ser imprescindível refletir acerca dos sistemas de representação e do entendimento de como as instituições sociais podem modificar os letramentos por meios de seus valores, regras e relações de poder estabelecidas pela força das comunidades.
Como a natureza não impõe o que se deve aceitar ou o modo como se deve levar a vida, pode-se identificar na geração digital um jeito novo de interpretar a realidade e intervir nela. A seleção natural não proíbe a cooperação e a generosidade entre os homens e as intenções e os objetivos estabelecidos em parceria instigam as funções cognitivas que permitem apreender os bens culturais e intervir na sociedade de modo peculiar e, por vezes, inesperado (PINKER, 1998).

O envolvimento social é tão relevante para o triunfo cognitivo da espécie humana quanto os fatores físicos; por isso, embora o cérebro não tenha mudado estruturalmente ao longo de séculos, a condição humana tem melhorado (PINKER, 1998). Muitas iniciativas estão vinculadas a essa visão, e os novos ambientes coletivos permitem que grupos estabeleçam novas práticas sociais e possam agir em prol de outro que teria menos capacidade de ação se operasse por conta própria, como explica Shirky (2011, p.104) ao discutir a cultura da participação que se vê em plena expansão, especialmente entre jovens letrados digitalmente:

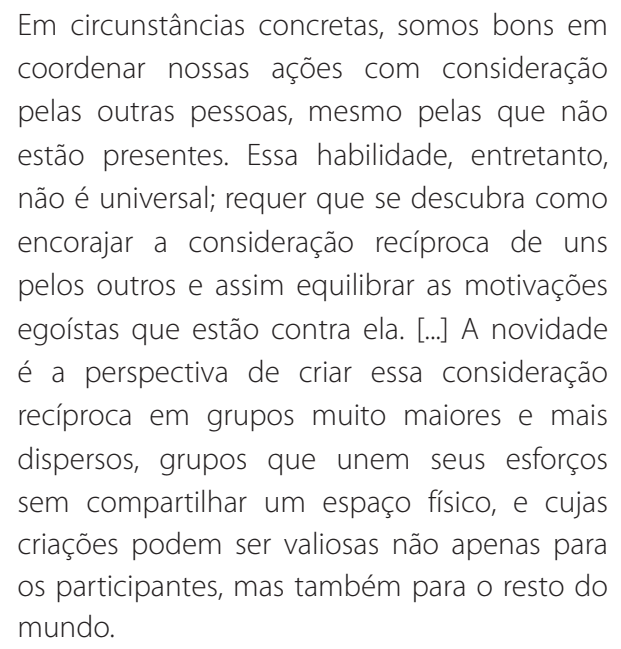

Essa perspectiva indica que no líquido mundo moderno as pessoas não nascem com identidades determinadas e as vivências possibilitam aos sujeitos assumirem a construção das identidades como 'tarefas'. com suas respectivas responsabilidades e consequências, configurando, assim, um tipo específico de autonomia, que não permite atribuir a mais ninguém o resultado das ações, seja ele positivo ou negativo (BAUMAN, 2001). 


\section{Letramento informacional}

Reconhece-se neste artigo a existência de múltiplos letramentos, os quais possibilitam aos sujeitos adaptarem-se em um mundo em transformação. Nos distintos tipos de letramento prevalece a ideia de desenvolvimento de capacidades específicas que favoreçam a resolução de problemas ou a tomada de decisão. Ou seja, a ideia de letramento traz em seu bojo a funcionalidade, que transcende o mero conhecimento, exigindo a aplicação deste em situações do cotidiano, em direção à criação de redes e comunidades de aprendizagem.

Se por um lado o letramento digital possibilita o desenvolvimento da capacidade de lidar com o universo digital, por outro lado o letramento informacional a amplia, ao propiciar o desenvolvimento de competências para buscar e usar criticamente a informação disponível em vários suportes e canais impressos e eletrônicos - por exemplo, livros, jornais, revistas científicas, audiovisuais, bases de dados, bibliotecas, dentre outros. Ao não considerar somente o ambiente digital, o letramento informacional propõe o equilíbrio entre o uso dos recursos tradicionais e dos digitais no processo de aprendizagem.

Isso porque, de acordo com Carr (2011), se o meio influencia o modo de pensar e de agir, então o uso predominante da Internet pode provocar efeitos negativos na forma como os aprendizes absorvem a informação. Ao invés de manter a mente focada e sem distrações, o que possibilitaria a capacidade de aprofundamento textual, o uso sistemático de recursos digitais torna-a mais inquieta, impaciente para leitura de artigos mais aprofundados, mais propensa ao escaneamento ocular rápido para identificar as informações necessárias, podendo saltar de um ponto a outro durante a leitura. Vê-se, com esse exemplo, o quanto o comportamento muda em consonância com o meio utilizado para apreender informações.

Como a profundidade da inteligência humana depende da capacidade de transferir informação da memória de trabalho para a memória de longo prazo a fim de tecer esquemas conceituais, é preciso haver mais equilíbrio entre as atividades em ambientes digitais e as atividades com textos lineares, que direcionam a concentração e impõem uma 'carga cognitiva' adequada à capacidade de processamento.

Corroborando essa ideia, Logan (2012), em sua mais recente obra, intitulada 'Que é informação?', afirma que o cérebro humano precisa do impresso. A pesquisa se baseia em estudos neurofisiológicos comparativos entre as leituras de textos em papel com uma tela eletronicamente configurada. Os resultados mostram que a leitura no papel restringe-se ao hemisfério esquerdo do cérebro, responsável pela interpretação da linguagem. Ao contrário disso, a leitura na tela eletrônica exige o envolvimento do lado direito também. Isso porque, por melhor que seja a resolução da tela, é necessário converter pixels em letras, para posteriormente convertê-las em palavras e frases. Tais ações demandam grande quantidade de tráfego pelo corpo caloso, dificultando a concentração e a imersão, e tornando a leitura mais cansativa. Além do aspecto neurofisiológico, a tecnologia do livro impresso permite maior liberdade no manuseio, sem o emperramento imposto pela rolagem. Assim, o autor defende a experiência conjugada do uso da Internet e do papel. Sugere, por exemplo, a impressão de textos e hiperlinks mais relevantes como prática seletiva útil, que permite atingir com mais eficiência os objetivos.

Alinhada a essa perspectiva, o foco do letramento informacional não abrange determinada fonte, canal ou ambiente, mas as atividades cognitivas necessárias para que se aprenda a buscar e usar a informação em vários suportes e ambientes, com o objetivo de transformá-la em conhecimento em prol da vida plena e da emancipação humana. De acordo com Sonnenwald (1999), isso requer lidar com as dimensões cognitivas, sociais, sistêmicas e ecológicas do ser humano. O sujeito letrado informacionalmente tem capacidade de resolver problemas e tomar decisões quando utiliza vários recursos de forma eficiente e eficaz, o que inclui a Internet, as redes sociais, os arquivos pessoais, a memória técnica das instituições, dentre outras fontes potenciais de informação, além de considerar também pontos de vistas e formatos diferentes que contribuem para a construção do conhecimento.

A expressão information literacy foi cunhada por Zurkoswski (1974) em um relatório escrito em nome da Comissão Nacional de Bibliotecas e Ciência 
da Informação dos Estados Unidos da América. No documento, ele recomendava sobre a necessidade de conscientizar os sujeitos quanto à importância do letramento informacional para a aquisição de competências informacionais, com foco no uso de fontes digitais. De acordo com Gasque (2010), os estudos intensificaram-se nas últimas duas décadas, chegando ao Brasil no início deste século, com o uso de várias expressões e termos, tais como letramento informacional, competência informacional e alfabetização informacional, dentre outros.

Pode-se observar, pela literatura da área, que o movimento em prol do letramento informacional tem potencial para ampliação de suas bases. Isso porque existe consenso de que a grande produção de informação na sociedade contemporânea requer novas formas de aprendizagem. Parafraseando Herbert Simon, ganhador do prêmio Nobel de Economia [1978], citado na obra "Como as pessoas aprendem" (BRANSFORD et al., 2007), o significado do saber mudou: mais importante do que memorizar informações, é preciso saber buscá-las e transformá-las em conhecimento para resolver as questões do cotidiano.

O letramento informacional pode ser compreendido, então, como processo de aprendizagem necessário ao desenvolvimento das seguintes competências, propostas pela Association of College and Research Library (2000). Os padrões de Letramento informacional, atualmente, passam por revisão realizada por uma força-tarefa, com o objetivo de abranger a complexidade dos novos recursos e tecnologias que surgiram, bem como os múltiplos letramentos (digital, visual, etc.), além de considerar aspectos como flexibilidade dos padrões, terminologia mais acessível, dentre outros, mas continuam válidas as listadas a seguir: (a) reconhecer a necessidade de informação e determinar a extensão da necessidade de informação; (b) acessar a informação de forma efetiva; (c) avaliar criticamente a informação; (d) incorporar as novas informações ao conhecimento prévio e usá-las para atingir objetivos e resolver problemas, e (e) compreender os aspectos econômicos, sociais e éticos do uso da informação para acessá-la e usá-la de forma ética e legal.

Um ponto destacado por Gasque (2012) é que o desenvolvimento dessas competências deve considerar a reflexão acerca dos processos de busca e uso da informação, que estão associados a determinadas práticas de leitura e escrita. Para que os sujeitos possam resolver problemas, precisam compreender o motivo de aprender determinado conteúdo e em que situações devem aplicá-lo.

Kahneman (2012), na obra "Rápido e Devagar: duas formas de pensar", argumenta sobre a importância de duvidar, questionar e refletir sobre as coisas, escolhas e opiniões. Muitas vezes, o cérebro humano, ao se deparar com um problema ou decisão, restringe previamente o leque de opções, movido pelo instinto de economia e sobrevivência, visto que escolher uma dentre várias opções pode levar a mente e o corpo à exaustão. Isso significa que nem sempre o indivíduo tem liberdade total para escolher ou decidir. O pensamento rápido, instintivo e emocional, enraizado na experiência, denominado pensamento intuitivo, pode ser explicado pela evolução. As emoções e instintos foram moldados desde os primeiros ancestrais, ao contrário do pensamento lento, lógico, reflexivo, surgido relativamente tarde com o córtex pré-frontal.

O pensamento reflexivo, como proposto por Dewey (1979), pode ser compreendido como processo similar ao método científico. Os indivíduos se deparam com a necessidade de tomar decisão ou resolver problemas, cujos resultados se vinculam à qualidade das informações e à forma de utilizá-las. Isso requer questionar, por exemplo, o tipo de informação necessária (científica, especializada ou atualidades), os bancos de dados específicos para determinada área de conhecimento, a autoria, a data da produção da obra e a linha de pesquisa do autor, bem como conhecer sistemas de busca e recuperação de informação. Além disso, é preciso conhecer estratégias para apreender a informação, como resumos, resenhas e mapas conceituais, além de dominar as normas específicas de produção textual. Grosso modo, é necessário saber pesquisar e investigar, considerando os aspectos legais, sociais e éticos da busca e do uso da informação, o que exige a participação em eventos específicos de letramento.

A questão é que, durante o processo de pesquisa ou tomada de decisão, às vezes, os sujeitos centralizam 
os esforços na compreensão dos conteúdos, em detrimento dos saberes necessários para produzir uma boa pesquisa. Em suma, o que se ressalta é que, nos processos de pesquisas e tomada de decisão, didaticamente, duas modalidades de conteúdos devem ser focalizadas: os conteúdos que abrangem o assunto a ser pesquisado, e os conteúdos necessários para a realização das pesquisas.

De acordo com Gasque (2012), o processo de ensino-aprendizagem deve ocorrer de modo sistematizado e formal no currículo ao longo da educação básica e, mais adiante, no ensino superior. A autora assegura que é possível ensinar conceitos necessários ao letramento informacional desde a educação infantil. Nessa faixa etária, os aprendizes podem ter noções sobre autor, títulos, ilustradores e ilustrações, ordem alfabética, coleta de dados, leitura com imagens, assim como podem diferenciar livros de ficção e não ficção, e aprender a usar a biblioteca escolar. Esse período, predominantemente caracterizado pelos primeiros contatos com os suportes de informação e pela compreensão de conceitos relacionados às práticas de busca e uso da informação, denomina-se alfabetização informacional.

No Ensino Fundamental 1, período que geralmente abrange a faixa etária de 7 a 10 anos, além de consolidar as noções estudadas na educação infantil, os estudantes podem aprender a manusear a Internet, ter noções de como se produzem pesquisas, aprender sobre as características e elementos presentes nos livros, revistas e jornais, conhecer gêneros como biografias e autobiografias. Outros objetivos a serem conquistados das normas de documentação, tais como citação e referência; o desenvolvimento de competências para organizar a informação por meio de técnicas de leitura e anotações, como fichamentos, esquemas, resumos, relatórios, glossários, mapas conceituais, e apresentá-la em seminários.

No ensino médio, além da consolidação dos conceitos aprendidos na fase anterior, o foco recai na estruturação da pesquisa em vários formatos de comunicação, tais como artigos, resenhas, dentre outros, como também nas questões vinculadas à filosofia da ciência.

Em resumo, os conteúdos da educação básica devem proporcionar diretrizes para a formação do jovem pesquisador, abrangendo: a filosofia da ciência; a introdução ao conceito de pesquisa e planejamento para resolução de problemas; o conhecimento da organização e arranjo de várias fontes e canais de informação em meio impresso e online, a utilização das novas tecnologias, como recursos de busca e disseminação da informação; a utilização de critérios adequados para avaliar os canais e as fontes de informação; a seleção, organização e relação entre dados e informações de vários autores com diferentes pontos de vista para sintetizá-los em um documento; a leitura, compreensão e identificação de informações relevantes e pertinentes aos diversos gêneros textuais; a compreensão do conceito de autoria e plágio; o conhecimento sobre como ocorre a produção científica; e a utilização da biblioteca. Os estudantes, também, devem desenvolver competência para a produção escrita de vários gêneros textuais. Observa-se nesse rol de atividades a inclusão de uma variedade enorme de práticas de letramento que requerem vivências e reflexões específicas.

Além disso, para desenvolver o letramento informacional, é imprescindível a organização dos conteúdos de aprendizagem e das estratégias de ensino. Ressalva-se que três fatores são fundamentais para o referido processo: a contextualização do conteúdo, o uso de modelos e a aplicação dos conteúdos em quantidade suficiente para que ocorra aprendizagem significativa - como propõe Zabala (1999) para os conteúdos com forte caráter procedimental. 
A aprendizagem significativa, conceito cunhado por Ausubel et al. (1980), indica que a nova informação a ser apreendida deve estar ancorada nas experiências prévias do aprendiz. Nesse sentido, a contextualização do conteúdo significa inserir o novo assunto na realidade do aprendiz, partindo dos conceitos que lhe são familiares. O uso de modelos refere-se à apresentação do processo e do produto a serem alcançados. E, por fim, colocar o conhecimento na prática é o exercício que permite ao aprendiz ser capaz de transferir o conhecimento para outras situações e contextos.

Torna-se evidente que essas competências não são inatas e devem ser construídas e desenvolvidas desde a educação básica para que se possam formar cidadãos letrados informacionalmente, que sejam capazes de produzir conhecimento de qualidade para participar efetivamente na sociedade.

\section{Conclusão}

O letramento é desenvolvido por meio de um conjunto de práticas sociais em que os sujeitos se envolvem de diferentes formas, considerando as demandas do contexto social, as habilidades e os conhecimentos de que dispõem. Tais práticas são designadas de práticas ou eventos de letramento, porque dão sentido aos usos da leitura e escrita e caracterizam um processo de formação que se prolonga ao longo da vida de cada pessoa e integra as atividades de diferentes grupos humanos, como foi destacado anteriormente.

As mediatizações humanas, que ocorrem entre pessoas, instituições e meios de informação e comunicação, indicam que as diversas interações podem sustentar o desenvolvimento dos sujeitos. Este estudo mostra que a interação mediatizada estimula a aprendizagem, a criatividade e a conexão entre as pessoas, o que fortalece a herança cultural de cada grupo social.

Dentre os múltiplos tipos de letramento, o digital e o informacional desenvolvem competências que favorecem novas conexões na sociedade contemporânea, por isso devem ser visto como um continuum que integra a busca e o uso de informações em diversos contextos e suportes informacionais. Mediante o de- senvolvimento de recursos e estratégias cognitivas para lidar com a informação e tomar de decisões, o sujeito amplia os modos de agir no mundo, tornando-se mais criativo e inovador.

Ressalta-se, no entanto, a importância de equilibrar as experiências com os recursos digitais e os tradicionais, por dois motivos: a existência de inúmeras mídias disponíveis fora do ambiente digital e os efeitos que o uso das novas tecnologias pode acarretar no cérebro humano.

Se a cultura é considerada uma força dinâmica que interliga e até condiciona continuidades e descontinuidades, o ciberespaço e os meios tradicionais de registro e veiculação de informações estimulam os sujeitos à ação, participando diretamente da constituição de suas identidades (ainda que estas possam não permanecer as mesmas por muito tempo). Ao assumirem a identidade como tarefa e objetivo de trabalho de toda uma vida, os sujeitos podem optar por realizar atos de libertação da inércia dos costumes tradicionais, das autoridades imutáveis, das rotinas preestabelecidas e das verdades inquestionáveis. Por ousar assumir riscos e ainda ter a coragem exigida pelo ato de fazer escolhas, a tripla confiança (em si mesmo, nos outros e na sociedade) torna-se absolutamente necessária para os sujeitos que venham a ser considerados letrados na sociedade contemporânea.

Ao passar da fase sólida da modernidade para a fase fluida, as formas conhecidas não se mantêm íntegras por muito tempo, por isso é tão importante saber como agir diante de situações inesperadas, ou seja, estar preparado para as possibilidades. Como a identidade do sujeito se constrói na língua e por meio das interações proporcionadas pelos eventos comunicativos, reconhece-se não haver identidade fixa fora e anterior aos processos de letramento, pois só se podem reconhecer identidades em estado de fluxo contínuo.

\section{Colaboradores}

Todos os autores contribuíram na concepção e desenho do estudo e redação final. 


\section{Referências}

ADOLPHS, R. Social cognition and the human brain. Trends in Cognitive Sciences, v. 3, n. 12, p. 469-479, 1999.

ANDERSON, J. Is human cognition adaptive? Behavioral and Brain Sciences, v. 14, n. 3, p. 471-484, 1991.

ASSOCIATION OF COLLEGE AND RESEARCH LIBRARY. Information literacy competency for higher education. Chicago: ALA, 2000. Available from: <www.ala.org/ala/mgrps/divs/ acrl/ standards/standards.pdf>. Cited: May 30, 2012.

AUSUBEL, D. P.; NOVAK, J.; HANESIAN, H. Psicologia Educacional. 2. ed. Rio de Janeiro: Interamericana, 1980.

BARTON, D.; HAMILTON, M. Local Literacies: Reading and writing in one community. London: Routledge, 1998.

BAUMAN, Z. Identidade: entrevista a Benedetto Vecchi. Rio de Janeiro: Jorge Zahar Editor, 2005.

BAUMAN, Z. Modernidade líquida. Rio de Janeiro: Jorge Zahar Editor, 2001.

BAUMAN, Z. Tempos líquidos. Rio de Janeiro: Jorge Zahar Editor, 2007.

BRANSFORD, J. D.; BROWN, A. L.; COCKING, R. R. (Org). Como as pessoas aprendem. São Paulo: Senac, 2007.

CARR, N. A geração superficial: o que a Internet está fazendo com os nossos cérebros. Rio de Janeiro: Agir, 2011.

CHOUDHURY, S.; McKINNEY, K. A. Digital media, the developing brain and the interpretive plasticity of neuroplasticity. Transcultural Psychiatry, v. 50, n. 2, p. 192-215, 2013.

DEWEY, J. Como pensamos: como se relaciona o pensamento reflexivo com o processo educativo, uma reexposição. 4. ed. São Paulo: Nacional, 1979.

DEWEY, J. Vida e educação. 10. ed. São Paulo: Melhoramentos, 1978.

FARRAR, L. Cell phone stories writing new chapter in print publishing. CNN: Digital Biz, Feb. 26, 2009. Available from: <http://edition.cnn.com/2009/TECH/02/25/japan.mobile novels/>. Cited: Sept. 28, 2012.

FISKE, S. T.; TAYLOR, S. E. Social cognition. New York: McGrawHill, 1991.

GASQUE, K. C. Letramento informacional: pesquisa, reflexão e aprendizagem. Brasília: Universidade de Brasília, 2012. Disponível em: <http://leunb.bce.unb.br/handle/12345678 9/22>. Acesso em: 10 maio 2012.

GASQUE, K. C. G. D. Arcabouço conceitual do letramento informacional. Ciência da Informação, v. 39, n. 3, p. 83-92, 2010. Disponível em: <http://www.scielo.br/scielo.php?script=sci_ arttext\&pid=S0100-19652010000300007\&lng=pt\&nrm=iso $>$. Acesso em: 24 nov. 2014. Acesso em: 24 nov. 2014.

KAHNEMAN, D. Rápido e devagar: duas formas de pensar. Rio de Janeiro: Objetiva, 2012.

LÉVY, P. As tecnologias da inteligência: o futuro do pensamento na era da informática. Rio de Janeiro: Editora 34, 1993.
LOGAN, R.K. Que é informação? A propagação da organização na biosfera, na simbolosfera, na tecnosfera e na econosfera. Rio de Janeiro: Contraponto, 2012.

MCLUHAN, M. Os meios de comunicação como extensões do homem. São Paulo: Cultrix, 1969.

MELLOW, P. The media generation: Maximise learning by getting mobile. In: ASCILITE CONFERENCE, 2005, Brisbane. Proceedings... Brisbane: Australasian Society for Computers in Learning in Tertiary Education, 2005. p. 469-476. Available from: <http://ascilite.org.au/conferences/brisbane05/blogs/ proceedings/53_Mellow.pdf>. Cited: Jun. 10, 2014.

MERZENICH, M. Built for change. [S.I.]: TED Ideas worth spreading, 2004. video (23 min.), son., color. Available from: <http://www.youtube.com/watch?v=Z41BTeAU7DI>. Cited: 6 May 2012.

MOSKOWITZ, G. B. Cognitive social psychology: The Princeton Symposium on the Legacy and Future of Social Cognition. Mahwah, NJ: Erlbaum, 2001.

MOSKOWITZ, G. B. Social cognition: Understanding self and others. New York: Guilford Press, 2005.

ONISHI, N. Thumbs race as Japan's best sellers go cellular. The New York Times, Jan. 20, 2008. Available from: <http:// www.nytimes.com/2008/01/20/world/asia/20japan.html? $r=1$ \&pagewanted=1>. Cited: Sept. 28, 2012.

PERRY, B. et al. Chilhood trauma, the neurobiology of adaptation, and "use-dependent" development of the brain: How "states" become "traits". Infant Mental Health Journal, v. 16, n. 4, p. 271-291, 1995.

PINKER, S. Como a mente funciona. São Paulo: Companhia das Letras, 1998.

PRENSKY, M. Digital natives, digital immigrants. On the Horizon, v. 9, n. 5, p. 1-9, 2001. MCB University Press.

PRENSKY, M. The Reformers are leaving our schools in the $20^{\text {th }}$ century. On the Horizon, Jan., p.1-18, 2011. SNS Newsletter.

SHIRKY, C. A cultura da participação: criatividade e generosidade no mundo conectado. Rio de Janeiro: Zahar, 2011.

SMALL, G.; VORGAN, G. Ibrain: Surviving the technological alteration of the modern mind. New York: Collins, 2008.

SOARES, M. Novas práticas de leitura e escrita: letramento na cibercultura. Educação e Sociedade, v. 23, n. 81, p. 143160, 2002. Disponível em: <http://www.cedes.unicamp.br>. Acesso em: 30 mar. 2012

SONNENWALD, D. H. Evolving perspectives of human information behavior: Contexts, situations, social networks and information horizons. In: WILSON, T.; ALLEN, D. Exploring the contexts of information behaviour. London: Taylor, 1999. p. 176-190. Available from: <http://dlist.sir.arizona. edu/1317/01/isic98+paper.pdf>. Cited: Apr. 3, 2012.

TAPSCOTT, D. Geração digital: a crescente e irreversível ascensão da Geração Net. São Paulo: Makron Books, 1999. 
TFOUNI, L. Letramento e alfabetização. São Paulo: Cortez, 2002.

XAVIER, A. C. Leitura, texto e hipertexto. In: MARCUSCHI, L. A.; XAVIER, A. C. Hipertexto e gêneros digitais: novas formas de construção do sentido. Rio de Janeiro: Lucerna, 2004.

XAVIER, A. C. Letramento digital e ensino. In: FERRAZ, C.; MENDONÇA, M. Alfabetização e letramento: conceitos e relações. Belo Horizonte: Autêntica, 2007.
ZABALA, A. Como trabalhar os conteúdos procedimentais em aula. Porto Alegre: Artmed, 1999.

ZURKOWSKI, P. The information service environment relationships and priorities. Washington, D.C.: National Commission on Libraries and Information Science, 1974. (Related Paper, 5). Available from: <http://files.eric.ed.gov/ fulltext/ED100391.pdf>. Cited: Nov. 24, 2014.
173

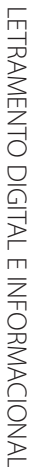


